\title{
The Psychological Impact of COVID-19 on Antenatal Women: A Scoping Review
}

Mohd Arifin SRM ${ }^{a}$, Hassan $N A^{b}$

${ }^{a}$ Department of Special Care Nursing, Kulliyyah of Nursing, International Islamic University Malaysia, Indera Mahkota Campus, 25200 Kuantan, Pahang, Malaysia

bepartment of Community Medicine, Kulliyyah of Medicine, International Islamic University Malaysia, Indera Mahkota Campus, 25200 Kuantan, Pahang, Malaysia

\section{ABSTRACT}

The widespread transmission of the new coronavirus disease COVID-19 has caused great psychological distress across diverse populations in many countries. Antenatal women are at greater risk of emotional instability and vulnerability due to hormonal changes, and multiple maternal roles. This paper aims to determine the common types of psychological distress and potential interventions amongst antenatal women during COVID19 outbreak. This review was conducted as a rapid review in response to the COVID-19 outbreak. The PubMed, Scopus, and Google Scholar databases were searched using keywords namely "novel coronavirus", "COVID-19", "nCoV”, “maternal mental health", "pregnant”, “psychology”, "anxiety”, “depression” and "stress" in various permutations and combinations. A total of five papers were included in the final analysis. Thematic analysis was used to analyse the selected papers. Findings from the papers reviewed showed that COVID-19 has independently increased the prevalence of psychological distress among antenatal mothers. The most common types of distress were anxiety $(57 \%-83.3 \%)$, followed by worry $(50.7 \%)$ and depression (34.2-37\%). The distress experienced by the antenatal women with COVID-19 was found to be associated with suicidal thought. Social support, psychological hotlines, and online counselling have been suggested to alleviate the symptoms of mental distress among antenatal women. The COVID-19 pandemic has independently caused psychological distress among antenatal women to rise. Maternal mental health should be prioritised during the pandemic, and mental support should be made available and accessible during and after the COVID-19 outbreak in ensuring the ongoing provision of mental health services.

KEYWORDS: women, maternal health, mental, COVID-19, psychological impact

\section{INTRODUCTION}

The outbreak of a new coronavirus disease, COVID19, was declared as a pandemic in March $2020 .^{1}$ It has widely spread in many geographical locations. To date (18 May 2020), over 4.5 million people have been affected by this disease and more than 300,000 deaths have been reported. ${ }^{1}$ The widespread transmission of COVID-19 along with the increasing number of infected cases and deaths have caused great psychological distress such as depression, anxiety, and stress across diverse populations in many countries. $^{2-3}$ These adverse mental health

Corresponding Author:

Asst. Prof. Dr. Siti Roshaidai Mohd Arifin

Department of Special Care Nursing, Kulliyyah of Nursing, International Islamic University Malaysia, Indera Mahkota Campus, 25200 Kuantan, Pahang, Malaysia.

Tel No : +609 - 5707200

Email : roshaidai@iium.edu.my consequences are associated with various factors such as being seriously worried about being infected, having no psychological support, disturbed sleep, and lower self-perceived health condition. ${ }^{3-5}$ Fake news and inaccurate updates about COVID-19, especially in social media, have created panic, insecurity, and fear among the public. ${ }^{6}$ Studies on COVID-19 and mental health have been conducted in various populations including children, adolescents, working adults, antenatal women, older adults, workers, medical staff, psychiatric inpatients, and university students. ${ }^{7-12}$

The medical community's preparedness effort is required in handling an outbreak of such a large scale, and this will be optimised when vulnerabilities are recognised and addressed through sound and ethical health policy. ${ }^{13}$ As of today, it is still unclear whether antenatal women are susceptible. Some 
literature suggest that antenatal women are more susceptible to COVID-19 because of their altered anatomy and physiology, and compromised mechanical and immunological functions. ${ }^{714-15} \mathrm{~A}$ COVID-19 infection during pregnancy may result in severe morbidity and mortality due to alterations in characteristic immune responses and potential risks from the cytokine-storm caused by the infection. ${ }^{15}$ While there is insufficient evidence supporting intrauterine vertical transmission, it is believed that maternal reaction towards such infection could affect the developing foetus and postnatal life. However, it has been argued that there is limited evidence to conclude that antenatal women are at higher risk of catching COVID-19 compared to the population as a whole. ${ }^{17-19}$

The uncertainty in determining women's vulnerability may lead to inaccurate management of antenatal women during the COVID-19 pandemic. For instance, the suspected mother is separated from her baby and refrained from breastfeeding until she has fully recovered or has been confirmed not to have COVID-19. ${ }^{20}$ Such practice not only impede early bonding and lactation but also create psychological distress during the postnatal period. ${ }^{17,20}$

It is well documented that the COVID-19 pandemic has led to feelings of helplessness and abandonment due to various sudden changes to normal life routines in women such as family organisation, childcare, the closing of schools/nursery, having to work from home, lock-down, and self-isolation. ${ }^{6}$

Nevertheless, the pandemic may bring in additional sources of distress related to concerns about their own health, worries of the health and safety of their unborn babies, and dilemma regarding the use of vaccines and medications for prophylaxis and treatment. ${ }^{21}$ On top of the distress created by the spread of COVID-19, antenatal women are exposed to the risk of emotional instability and vulnerability due to multifaceted factors such as hormonal changes, changes in body image, multiple maternal roles, and tradition-modernity conflicts. ${ }^{22-23}$ It was reported that $18.2-24.6 \%$ and $4-63.9 \%$ of women were affected by antenatal anxiety and postnatal depression, respectively. ${ }^{23-24}$

Studies have shown that antenatal women experienced psychological distress due to disruptions to routine maternal and child health care during previous large scale infectious disease outbreaks such as severe acute respiratory syndrome (SARS), Zaire ebolavirus (Ebola), and Zika. ${ }^{25-29}$ For instance, the suspension of antenatal services in Hong Kong and limited time spent in the hospital after giving birth in Taiwan during the SARS outbreak in 2004 resulted in distress among the affected women. ${ }^{25-26}$ There is evidence that anxiety and anticipatory worries were common among antenatal women during the SARS outbreak. ${ }^{26}$ The sources of anxiety and worries were traced to concerns of getting infected, transmitting the infection to the unborn baby, risking teratogenicity should drug treatment be required, and losing their jobs or being subjected to salary cuts. ${ }^{26-27}$ After the outbreak of the Ebola in Guinea in 2014, the Ebola survivors especially women of reproductive age, not only experienced emotional distress, discrimination, and difficulty regaining their livelihoods but were also worried of recurrence of the virus during or after pregnancy. ${ }^{28}$ In 2015 , the widespread infection of Zika virus had caused worries and fears among many antenatal women, particularly when Brazil reported an association between the Zika virus infection and foetal microcephaly. ${ }^{29}$

Whilst there is evidence of the psychological impact of COVID-19 on the general population, there are limited review papers that could summarise its impact on antenatal women. Without such knowledge, appropriate care and support for maternal mental health are not optimally provided within the clinical practice. ${ }^{16}$ Therefore, this paper aims to determine the common types of psychological distress and their prevalence among antenatal women during the COVID-19 outbreak.

\section{MATERIAL AND METHODS}

This study was conducted as a rapid review in response to the COVID-19 outbreak. Although this review followed the general guidelines for systematic reviews, the grey literature was not searched, quality appraisal of the included papers was not performed, and foreign-language papers were not translated. ${ }^{21}$ This method is recommended when evidence synthesis is urgently required to inform public health guidelines. ${ }^{30}$ 
The PubMed, Scopus, and Google Scholar databases were searched using the keywords namely "novel coronavirus", “COVID-19”, “nCoV”, “maternal mental health”, “pregnant”, “psychology”, “anxiety”, "depression", and "stress" in various permutations and combinations. The inclusion criteria for the papers were: quantitative or qualitative data collection and analysis were used, conducted among antenatal women, included findings on the psychological impact of COVID-19, and published in English between 2019 and 2020. Papers were assessed for their eligibility through three different stages of screening; the title, abstract, and full text. A total of 83 papers were retrieved. Following the eligibility assessment, 78 papers were excluded and only five papers were included in the final analysis. Reasons for the exclusion are presented in Figure 1.

Thematic analysis was used to analyse the selected papers. Following this approach, findings from the papers were read line-by-line. Relevant ideas were coded throughout the reading. Based on the coding, the 'descriptive themes' were developed. The coding was compared across the selected papers. The 'descriptive themes' were then analysed and new constructs (analytical themes) were developed. ${ }^{20}$

\section{FINDINGS}

A total of five papers were included in this review. Three of the studies were conducted in China and one each in Ireland and Canada. Three of them were cross -sectional surveys and two were case reports. All three cross-sectional studies aimed to assess the mental impact, including anxiety and depression, of the COVID-19 outbreak on antenatal women. ${ }^{10,31-32}$ Whilst one of the case reports aimed to examine the effectiveness of dialectical behaviour therapy-based (DBT-based) psychological intervention in alleviating depression and anxiety in antenatal women, ${ }^{33}$ another case report presented a study on antenatal women infected with COVID-19. ${ }^{34}$ Edinburgh Postnatal Depression Scale (EPDS) was used in two studies to determine the prevalence of depression. ${ }^{10,31}$ The Hamilton Depression Rating Scale (HAMD-17), Hamilton anxiety (HAMA), and Montgomery-Asberg Depression Rating Scale (MADRS) were used in a study to determine the effectiveness of the DBT-based psychological intervention. The studies reviewed used various instruments to measure anxiety, including the PROMIS Anxiety Adult 7-item short form, a 10-item questionnaire about feelings surrounding the health of the baby and circumstances of the birth, and a self-developed questionnaire on attitudes and behaviour relating to COVID-19. Details of the aim, methods, and characteristics of each study are presented in Table 1.

Following the process of data analysis, three themes were identified: i) increasing prevalence, ii) risk factors, and iii) the need for interventions.

\section{Increasing prevalence}

Findings from the papers reviewed showed that COVID-19 has independently increased the prevalence of psychological distress such as depression and anxiety among antenatal mothers as highlighted in three studies. ${ }^{10,31-32}$ Only two studies reported depression with the prevalence ranging from $34.2 \%$ to $37 \%{ }^{10,31}$ Both of these studies used EPDS to assess the symptoms of depression, which explains the similarity in their results. Meanwhile, only two studies reported the prevalence of anxiety, ranging from $57 \%$ to $83.3 \% .^{31-32}$ This wide range of prevalence could be influenced by the use of different instruments. Whilst Lebel et al. ${ }^{31}$ adopted the PROMIS Anxiety Adult 7-item short form, Corbet et al. $^{32}$ on the other hand used a self-developed questionnaire on attitudes and behaviour relating to COVID-19 to determine anxiety in their study. Corbet et al. ${ }^{32}$ reported worries with a prevalence of $50.7 \%$.

A study among 4124 antenatal women from 25 hospitals in China found that the prevalence of depression increased up to $34.2 \%$ with the number of announcements of death and newly-diagnosed cases of COVID-19. ${ }^{10}$ Lebel et al. ${ }^{31}$ reported a higher prevalence of depression and anxiety related to COVID-19 in Canada. They conducted an online survey among 1987 antenatal women to evaluate the symptoms of anxiety and depression and the associated factors during the outbreak of COVID-19. They found that $37 \%$ of antenatal mothers had depression, 59\% had anxiety, and $67 \%$ had pregnancy -specific anxiety, which were substantially higher than in previous community pregnancy cohorts with similar demographic profiles. Corbett et al. ${ }^{32}$ assessed maternal anxiety due to COVID-19 and adaptation in behaviour among 71 antenatal mothers in their second and third trimester of pregnancy in an out-patient department in Ireland. They found that $50.7 \%$ of antenatal women were 


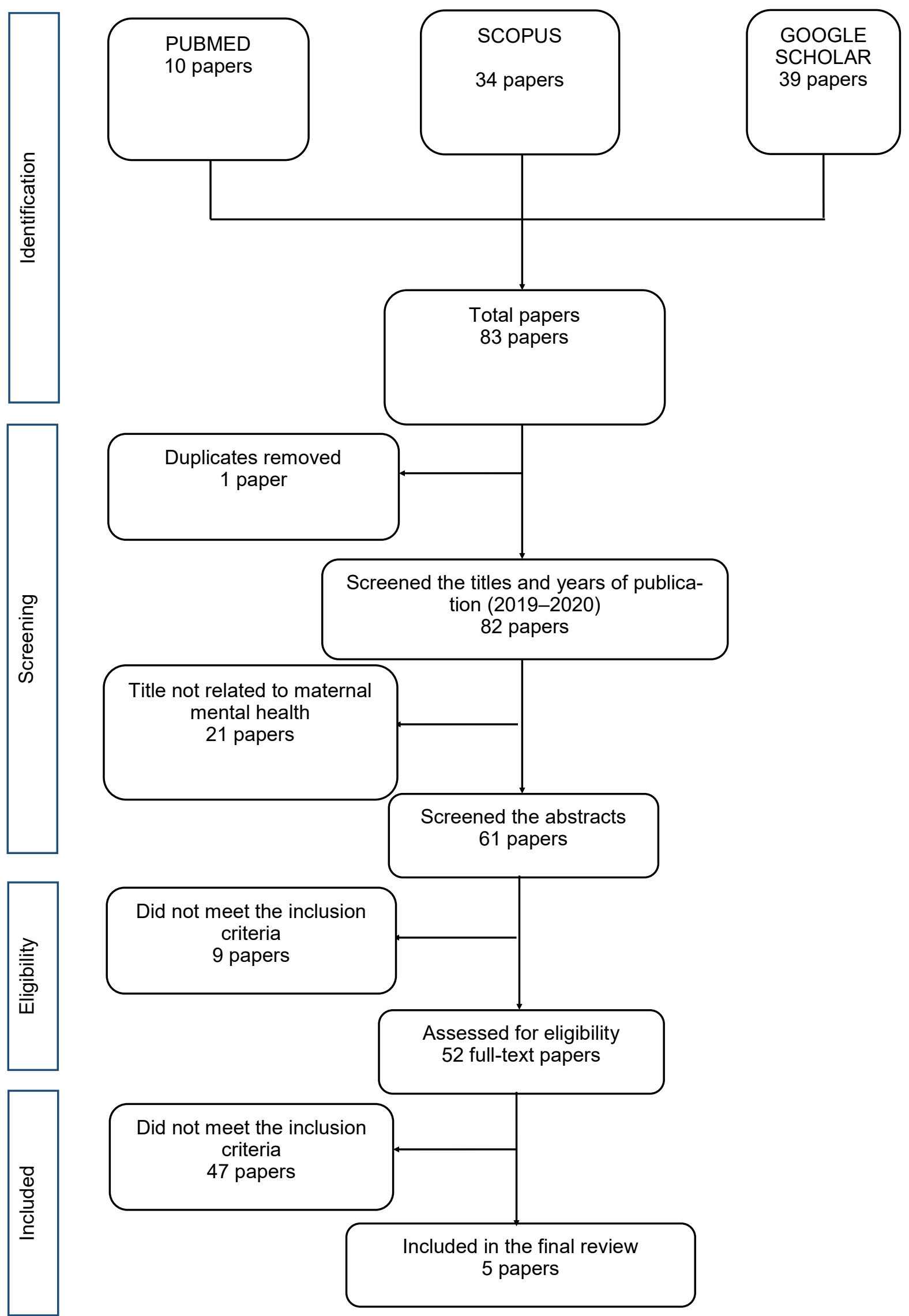

Figure 1: Search strategy 
worried about their health with the outbreak of COVID-19.

Psychological distress experienced by the antenatal women with COVID-19 was found to be associated not only with suicidal thought $^{10}$ but also with preterm delivery. ${ }^{34}$ On top of these potential impact, antenatal women were also concerned about the health and safety of their older relatives, children, and unborn child. ${ }^{10,31-32}$ It is due to these concerns that they isolated themselves, made bulk-buying, stayed at home, and worked from home. ${ }^{32}$

\section{Risk factors}

The risk factors for psychological distress were not discussed by all except in one study. Low socioeconomic status $(\mathrm{RR}=0.70,95 \% \mathrm{Cl}$ : $0.56-2.26, P$ $<0.001$ ), per-capita living area of smaller than 20 square meters $(\mathrm{RR}=1.41,95 \% \mathrm{Cl}: 1.07-1.85, P=$ $0.013)$, lower education levels $(R R=0.76,95 \% \mathrm{Cl}$ : $0.58-0.98, P=0.037$ ), without brothers or sisters ( $R R$ $=1.22,95 \% \mathrm{Cl}: 1.04-1.42, P=0.012)$, inadequate social support (RR=2.33, 95\% Cl: 1.12-4.86, $P=0.024)$, lacking in physical activities (AR=12.1, 95\% Cl: 1.123.1, $P=0.031$ ), being underweight, full-time employees, primiparous, and maternal age less than 35 years were identified as risk factors contributing to psychological distress among antenatal women. ${ }^{10}$ Predictably; this study reported that women with usually normal or even low risk of depression became more vulnerable to postnatal depression after the outbreak. $^{10}$

\section{The need for interventions}

Four of the papers reviewed suggested several potential interventions, namely social support, adequate sleep, psychological hotlines, and online counselling to alleviate the symptoms of mental distress among antenatal women. ${ }^{10,31-33}$ It was reported that increased social support and adequate sleep duration resulted in the reduction of psychological distress among antenatal women. ${ }^{31}$ Women with inadequate sleep were reported as having significantly worse symptoms of depression and anxiety. Moreover, Huang et al. ${ }^{33}$ evaluated the effectiveness of dialectical behaviour therapy-based psychological intervention to reduce the symptoms of depression and anxiety for a woman in late pregnancy and early postnatal suffering from COVID19. The techniques of mindfulness and relaxation exercise, distress tolerance skills, and interpersonal relationship skills applied in this therapy were found to reduce the symptoms of depression and anxiety. They concluded that a well-timed intervention is required for antenatal women with an infectious disease as they are dealing with not only the disease but also the childbirth and delivery.

Other suggestions include recruiting women who have experienced psychological distress as volunteers to provide peer support. Two studies highlighted the urgent need for interventions for antenatal women's mental health during the campaign against the COVID -19 pandemic. ${ }^{10,31}$ It was suggested that the women should be screened for postnatal depression and accessible support should be provided for them.

\section{DISCUSSION}

The increased prevalence of psychological distress, as reflected in the studies reviewed indicated that antenatal women are at greater risks of developing distress due to the widespread transmission of the COVID-19 pandemic. The most common types of distress were anxiety (57\%- 83.3\%), followed by worry (50.7\%) and depression (34.2-37\%). Concerns related to the safety of the unborn child, children, and older relatives were identified as common causes of the distress. Similar findings were recorded in the existing studies. ${ }^{21,35}$ The outbreak of infectious disease has been associated with anxiety, distress, fear, and uncertainty among pregnant mothers. ${ }^{21}$ For instance, the declaration of COVID-19 in China has led to an increase in negative emotions such as depression, anxiety, and indignation along with a decrease in positive emotions and life satisfaction. ${ }^{35}$

Dramatic and swift changes in the environment have made people notice that their common norms and behaviour no longer work. This is known as "evolutionary mismatch". ${ }^{36}$ Together with these changes, the COVID-19 outbreak makes people feel anxious and unsafe especially when information about the disease is vague, fake news is rampant, and management and treatment are unspecified. ${ }^{37}$ Moreover, quarantine and lock-down applied during this pandemic not only lead to negative psychological effects but also increase the risk of domestic violence, divorce, and separation. ${ }^{21,38-39}$ Being pregnant and giving birth during this undetermined pandemic period, therefore increase uncertainty and worries for many women and may further add to 
Table 1: Characteristics of the Included Papers

\begin{tabular}{|c|c|c|c|c|c|c|}
\hline Country & Authors & Objectives & $\begin{array}{l}\text { Research } \\
\text { design }\end{array}$ & Study population & $\begin{array}{l}\text { Measures (Tools) } \\
\text { used }\end{array}$ & Results \\
\hline \multirow[t]{2}{*}{ China } & \multirow[t]{2}{*}{$\begin{array}{l}\text { Wu et } \\
\text { al. }^{10}\end{array}$} & \multirow[t]{2}{*}{$\begin{array}{l}\text { To explore the } \\
\text { mental impact } \\
\text { of the COVID- } \\
19 \text { outbreak on } \\
\text { antenatal } \\
\text { women }\end{array}$} & \multirow[t]{2}{*}{$\begin{array}{l}\text { Cross- } \\
\text { sectional } \\
\text { survey }\end{array}$} & \multirow[t]{2}{*}{$\begin{array}{l}4124 \text { antenatal } \\
\text { women in their } \\
\text { third trimester } \\
\text { from } 25 \text { hospitals } \\
\text { in } 10 \text { provinces in } \\
\text { China }\end{array}$} & \multirow[t]{2}{*}{$\begin{array}{l}\text { Edinburgh Postnatal } \\
\text { Depression Scale } \\
\text { (EPDS) }\end{array}$} & $\begin{array}{l}34.2 \% \text { of the women } \\
\text { had depression } \\
\text { Several high-risk } \\
\text { factors were } \\
\text { identified for the } \\
\text { occurrence of } \\
\text { depression, e.g., } \\
\text { low socioeconomic } \\
\text { status, inadequate } \\
\text { social support, and } \\
\text { lack of exercise }\end{array}$ \\
\hline & & & & & & $\begin{array}{l}\text { There was a } \\
\text { significant increase } \\
\text { in the proportion of } \\
\text { women with } \\
\text { thoughts of self- } \\
\text { harm }\end{array}$ \\
\hline \multirow[t]{4}{*}{ Canada } & \multirow[t]{4}{*}{$\begin{array}{l}\text { Lebel et } \\
\text { al. }{ }^{31}\end{array}$} & \multirow{4}{*}{$\begin{array}{l}\text { To assess the } \\
\text { symptoms of } \\
\text { anxiety and } \\
\text { depression, } \\
\text { and their } \\
\text { associated } \\
\text { factors among } \\
\text { antenatal } \\
\text { women during } \\
\text { the current } \\
\text { COVID-19 } \\
\text { pandemic }\end{array}$} & \multirow[t]{4}{*}{$\begin{array}{l}\text { Cross- } \\
\text { sectional } \\
\text { survey }\end{array}$} & \multirow[t]{4}{*}{$\begin{array}{l}1987 \text { pregnant } \\
\text { participants }\end{array}$} & $\begin{array}{l}\text { Online survey: } \\
\text { EPDS } \\
\text { The PROMIS Anxiety } \\
\text { Adult 7-item short } \\
\text { form }\end{array}$ & $\begin{array}{l}37 \% \text { of the women } \\
\text { reported } \\
\text { depression, } 57 \% \text { had } \\
\text { anxiety, and } 68 \% \\
\text { experienced } \\
\text { pregnancy-related } \\
\text { anxiety }\end{array}$ \\
\hline & & & & & $\begin{array}{l}\text { A } 10 \text {-item } \\
\text { questionnaire } \\
\text { about feelings } \\
\text { surrounding the } \\
\text { health of the baby } \\
\text { and circumstances } \\
\text { of the birth }\end{array}$ & $\begin{array}{l}\text { Higher levels of } \\
\text { social support and } \\
\text { longer sleep } \\
\text { duration were } \\
\text { associated with } \\
\text { lower psychological } \\
\text { symptoms }\end{array}$ \\
\hline & & & & & $\begin{array}{l}\text { Social support } \\
\text { effectiveness } \\
\text { questionnaire } \\
\text { (SSEQ) }\end{array}$ & \\
\hline & & & & & $\begin{array}{l}\text { Interpersonal } \\
\text { support evaluation } \\
\text { list (ISEL) }\end{array}$ & \\
\hline Ireland & $\begin{array}{l}\text { Corbett } \\
\text { et al. }{ }^{32}\end{array}$ & $\begin{array}{l}\text { To assess } \\
\text { maternal } \\
\text { anxiety due to } \\
\text { COVID-19, } \\
\text { adaptations in } \\
\text { behaviour, and } \\
\text { information } \\
\text { sources used by } \\
\text { antenatal } \\
\text { women }\end{array}$ & $\begin{array}{l}\text { Cross- } \\
\text { sectional } \\
\text { survey }\end{array}$ & $\begin{array}{l}71 \text { antenatal } \\
\text { women in their } \\
\text { second and third } \\
\text { trimester of } \\
\text { pregnancy }\end{array}$ & $\begin{array}{l}\text { Self-developed } \\
\text { questionnaire on } \\
\text { attitudes and } \\
\text { behaviour relating } \\
\text { to COVID-19 }\end{array}$ & $\begin{array}{l}50.7 \% \text { of the women } \\
\text { were worried about } \\
\text { their health often } \\
\text { or all the time. } \\
\text { Pregnant women } \\
\text { had heightened } \\
\text { anxiety regarding } \\
\text { their older } \\
\text { relatives' health } \\
(83.3 \%) \text { and } \\
\text { concerns about } \\
\text { their other children } \\
(66.7 \%) \text { and unborn } \\
\text { baby }(63.4 \%)\end{array}$ \\
\hline
\end{tabular}


Con't

\begin{tabular}{|c|c|c|c|c|c|c|}
\hline Country & Authors & Objectives & $\begin{array}{l}\text { Research } \\
\text { design }\end{array}$ & Study population & $\begin{array}{l}\text { Measures (Tools) } \\
\text { used }\end{array}$ & Results \\
\hline China & $\begin{array}{l}\text { Huang } \\
\text { et al. }\end{array}$ & $\begin{array}{l}\text { To examine the } \\
\text { effectiveness } \\
\text { of dialectical } \\
\text { behaviour } \\
\text { therapy (DBT)- } \\
\text { based } \\
\text { psychological } \\
\text { intervention in } \\
\text { alleviating } \\
\text { depression and } \\
\text { anxiety in } \\
\text { antenatal } \\
\text { women }\end{array}$ & Case report & $\begin{array}{l}\text { One antenatal } \\
\text { woman with } \\
\text { COVID-19 at 35- } \\
\text { week of } \\
\text { pregnancy }\end{array}$ & $\begin{array}{l}\text { Three sessions of } \\
\text { DBT-based } \\
\text { psychological } \\
\text { intervention. } \\
\text { Instruments used: } \\
\text { Hamilton } \\
\text { Depression Rating } \\
\text { Scale (HAMD-17), } \\
\text { Hamilton anxiety } \\
\text { (HAMA), and } \\
\text { Montgomery-Asberg } \\
\text { Depression } \\
\text { Rating Scale } \\
\text { (MADRS) }\end{array}$ & $\begin{array}{l}\text { DBT-based } \\
\text { psychological } \\
\text { intervention was } \\
\text { effective in } \\
\text { reducing depression } \\
\text { and anxiety }\end{array}$ \\
\hline China & $\begin{array}{l}\text { Khan et } \\
\text { al. } .^{34}\end{array}$ & $\begin{array}{l}\text { To present a } \\
\text { case report on } \\
\text { antenatal } \\
\text { women } \\
\text { infected with } \\
\text { COVID-19 }\end{array}$ & Case report & $\begin{array}{l}\text { Three antenatal } \\
\text { women infected } \\
\text { with COVID-19 }\end{array}$ & A case report study & $\begin{array}{l}\text { The preterm } \\
\text { delivery might have } \\
\text { been caused by } \\
\text { psychological stress } \\
\text { associated with } \\
\text { COVID-19 during } \\
\text { pregnancy }\end{array}$ \\
\hline
\end{tabular}

their own mental burden and compromise their maternal role transition. ${ }^{22}$

Although Topalidou et al. ${ }^{16}$ have argued that there is limited evidence to conclude that the COVID-19 pandemic has negative impact on maternal mental health, they believe that the psychological impact of COVID-19 should be acknowledged as a serious public health concern which requires appropriate care and support. This current review adds that depression and anxiety experienced by antenatal women are significantly linked to suicidal thoughts. Although the association between suicidal thought and mental illness have been consistently found in many studies, this was studied in a normal situation and not during an outbreak of infectious disease. ${ }^{40-41}$ There is a possibility that the COVID-19 outbreak increases the suicidal ideation in antenatal women due to intense circumstances and various factors leading to loneliness, frustration, excessive worries, and uncertainty. Healthcare practitioners working in mental health care, should be prepared and work on relevant suicide prevention strategies.

The outcome of this review addresses the usefulness of social support, adequate sleep, and psychological intervention in preventing and managing the psychological impact of COVID-19 among antenatal women. Although professional intervention would be the most trustworthy resource for managing psychological distress, it should be noted that the accessibility of such intervention is limited during the pandemic outbreak. Therefore, non-professional approaches, including social support and religious approach, are imperative in protecting women from negative psychological impact. Social support has been widely recognised as an important strategy in coping with various maternal mental disorders such as antenatal anxiety and postnatal depression both during a pandemic and normal situation. ${ }^{21,42-43}$

While the risk factors for psychological distress have been discussed within this review, it could not be concluded if the risk factors such as low socioeconomic status, being underweight, full-time employees, and primiparous, are applicable for women in other countries as it was only discussed in one study in China. Nevertheless, it is worth noting that both women with normal and low risk of depression are equally vulnerable to postnatal depression during this pandemic. ${ }^{10}$

\section{Implications for healthcare practice}

Consistent with the studies on infectious disease outbreak, this review suggests that the COVID-19 pandemic may also lead to a burdensome atmosphere of fear, anxiety, depression, worries, and uncertainty within local communities and the whole world. ${ }^{21,26,44}$ Antenatal women in the studies reviewed were reported as being concerned because of the social distancing and self-isolation measures recommended by governments worldwide. Lee et al. ${ }^{26}$ also found that during the SARS outbreak, 
depressed or anxious antenatal women defaulted their antenatal check-up due to the fear of being infected. These findings highlight the importance of giving attention to maternal mental health during the pandemic. In this global crisis, it is important to ensure they receive accurate information from reliable sources so that the psychological impact will be reduced. ${ }^{32}$ There is a need to consider psychological hotlines and online healthcare services rather than in person. ${ }^{10,45}$ Consultation via telephone or internet could be used to ensure the ongoing provision of mental health services in supporting maternal mental health throughout the COVID-19 outbreak. ${ }^{46}$

Although the psychological impact of the COVID-19 pandemic are comparable to those of the previous pandemics such as SARS and Ebola, we found that the COVID-19 pandemic had resulted in increase in the prevalence of both depression and anxiety. A previous study noted an elevated rate in anxiety but no substantial increase in depression among the SARS cohort. ${ }^{26}$ This review adds that depression and anxiety experienced by antenatal women during this pandemic period are significantly linked to suicidal thoughts. Therefore, there is an urgent need for relevant interventions, including social support and online psychological counselling, to improve maternal mental health and prevent suicidal attempts during the COVID-19 pandemic.

Given that social support is imperative in protecting antenatal women and alleviating their psychological disorders, training of representatives from local communities as informal caregivers might be forthcoming. To do this, they should be trained to recognise the signs and symptoms of psychological distress and to alleviate the associated symptoms during this pandemic crisis. It is also worth considering recruiting women who had experienced psychological distress to provide peer support, as suggested by one of the studies reviewed. ${ }^{10}$ However, a proper guideline for this implementation is required, and special attention needs to be paid to ensure that informal caregivers are supported, informed, and protected. ${ }^{47}$

Worldwide, there should be established procedures for psychological crisis interventions to deal with public health emergencies and this should be targeted and adapted as appropriate with the inclusion of antenatal women as one of the special or vulnerable groups. ${ }^{48}$ Future research is warranted to determine the vertical transmission of COVID-19 and to investigate both the physical and psychological impact of an infectious disease outbreak on antenatal women. Without this understanding, the management of the women during the outbreak is not definitive. For example, stopping breastfeeding and separating a mother suspected with COVID-19 from a healthy baby may result in not only detrimental effects on feeding and bonding but also postnatal distress among new mothers. $^{49}$

There should be investments in research and strategic actions for maternal mental health in parallel with infectious disease outbreaks like COVID -19 to support the implementation of evidencebased practice in caring for antenatal women. It is this evidence that makes their care absolute and able to prevent unnecessary psychological distress.

\section{CONCLUSION}

This review has added on to the knowledge that the COVID-19 pandemic has independently caused psychological distress among antenatal women to rise. Depression and anxiety among antenatal women were found to be associated with suicidal thoughts. With the rapid evolution of COVID-19, this review suggests that maternal mental health should be prioritised during the pandemic as it will not only increase the likelihood of the mother to develop psychological distress but also affect maternalinfant bonding due to inconclusive management of COVID-19 within healthcare settings. Maternal mental health support should be made available and accessible during and after the COVID-19 outbreak to ensure the ongoing provision of mental health services. There is potential to provide social support by training representatives from local communities as informal caregivers for maternal mental health during this outbreak. A trustworthy procedure is required to address antenatal women as one of the special or vulnerable groups during any public health emergencies like COVID-19.

\section{REFERENCES}

1. WHO, Coronavirus (COVID-19) pandemic [online]. Available at: https://www.who. int/ emergencies/diseases/novel-coronavirus-2019 
Accessed May 18, 2020.

2. Bo HX, Li W, Yang $Y$, et al. Posttraumatic stress symptoms and attitude toward crisis mental health services among clinically stable patients with COVID-19 in China. Psychol Med 2020; 27:1 $-7$.

3. Rajkumar RP, COVID-19 and mental health: A review of the existing literature. Asian J Psychiatr. 2020 Aug; 52: 102066.

4. Altena E, Baglioni C, Ellis JG, et al. Dealing with sleep problems during home confinement due to the COVID-19 outbreak: practical recommendations from a task force of the European CBT-I academy. J Sleep Res 2020 Apr 4.

5. Li N, Han L, Peng M, et al. Maternal and neonatal outcomes of pregnant women with COVID-19 pneumonia: a case-control study, Clin Infect Dis 2020.

6. Ornell F, Schuch JB, Sordi AO, et al. "Pandemic fear" and COVID-19: mental health burden and strategies. Braz J Psychiatry 2020; 3.

7. Chen Y, Li Z, Zhang YY, et al. Maternal health care management during the outbreak of coronavirus disease 2019. J Med Virol 2020.

8. Li S, Zhang Y. Mental healthcare for psychiatric inpatients during the COVID-19 epidemic. Gen Psych 2020; 33: e100216.

9. Hiremath $\mathrm{P}$, Kowshik CSS, Manjunath $\mathrm{M}$, et al. COVID 19: Impact of lock-down on mental health and tips to overcome. Asian J Psychiatr 2020.

10. Wu U, Zhang $\mathrm{C}$, Liu $\mathrm{H}$, et al. Perinatal depression of women along with 2019 Novel Coronavirus breakout in China. SSRN Electronic Journal 2020.

11. Yang $\mathrm{H}$, Hou W, \& Zhang Y. Clinical characteristics and intrauterine vertical transmission potential of COVID-19 infection in nine pregnant women: a retrospective review of medical records, Lancet 2020; 395(10226): 809-815.

12. Zhang SX, Wang $Y$, Rauch A, et al. Unprecedented disruption of lives and work: Health, distress and life satisfaction of working adults in China one month into the COVID-19 outbreak. Psychiatry Res 2020; 4:288:112958.

13. Farrell RM, Beigi RH. Pandemic Influenza and pregnancy: an opportunity to reassess maternal bioethics. Am J Public Health. 2009 Oct; 99 (Suppl 2): S231-S235.
14. Alfaraj SH, Al-Tawfiq JA, Memish ZA. Middle East respiratory syndrome coronavirus (MERS$\mathrm{CoV}$ ) infection during pregnancy: Report of two cases \& review of literature. J Microbiol Immunol Infect 2019; 52:501-503.

15. Liu H, Liu F, Li J.et al. Clinical and CT imaging features of the covid-19 pneumonia: Focus on pregnant women and children, $J$ Infect 2020; 80(5):e7-e13.

16. Topalidou A, Thomson G, Downe S. COVID-19 and maternal mental health: Are we getting the balance right? BMJ 2020.

17. Wang $X$, Zhou Z, Zhang J, et al. A case of 2019 Novel Coronavirus in a pregnant woman with preterm delivery. Clin Infect Dis 2020; Feb 28.

18. Chen H, Guo J, Wang C, et al. Clinical characteristics and intrauterine vertical transmission potential of COVID-19 infection in nine pregnant women: a retrospective review of medical records. Lancet 2020; 7:395 (10226):809-815.

19. Chua M, Lee J, Sulaiman S, et al. From the frontline of COVID-19 - How prepared are we as obstetricians: a commentary. BJOG, 2020 Mar 4.

20. Arifin SRM, Cheyne H, Maxwell M. Crosscultural experience of maternal postnatal depression. Int J Psychosoc Rehabil 2020; 24 (3): 147-156.

21. Brooks SK, Webster RK, Smith LE, et al. The Psychological Impact of Quarantine and How to Reduce It: Rapid Review of the Evidence. Lancet 2020; 395:912-920.

22. Holditch-Davis D, Santos H, Levy J, et al. Patterns of psychological distress in mothers of preterm infants. Infant Behav Dev 2015, 41:154-163.

23. Arifin SRM, Cheyne H, Maxwell M. Review of the prevalence of postnatal depression across cultures. AIMS Public Health 2018; 5(3):26095.

24. Dennis CL, Falah-Hassani K, Shiri R. Prevalence of antenatal and postnatal anxiety: systematic review and meta-analysis. Br J Psychiatry 2017; 210: 315-23.

25. Lee, CH., Huang, N., Chang, H-J., Hsu, Y-J., Wang, M-C. \& Chou, Y-J. (2005). The immediate effects of the severe acute respiratory syndrome (SARS) epidemic on childbirth in Taiwan. BMC Public Health, 5, 30. 
26. Lee DTS, Sahota D, Leung TN, et al. Psychological responses of pregnant women to an infectious outbreak: A case-control study of the 2003 SARS outbreak in Hong Kong. J Psychosom Res 2006; 61:707- 713.

27. Ng J, Sham A, Tang PL, et al. SARS: Pregnant women's fears and perceptions. $\mathrm{Br} \mathrm{J}$ Midwifery 2013; 12(11).

28. Haddad LB, Jamieson DJ, Rasmussen SA, Pregnant Women and the Ebola Crisis. N Engl J Med 2018; 379:2492-2493.

29. WHO, Zika virus [online]. Available at: https://www.who.int/news-room/factsheets/detail/zika-virus Accessed May 5, 2020.

30. WHO. Rapid reviews to strengthen health policy and systems: a practical guide [online] 2017. Available at: https://www.who.int/ alliance-hpsr/resources / publications/rapidreview-guide/en/ [Accessed May 4, 2020]

31. Lebel C, MacKinnon A, Bagshawe M, et al. Elevated depression and anxiety among pregnant individuals during the COVID-19 pandemic. PsyArXiv [online] 2020. Available at: https://psyarxiv.com/gdhkt/ Accessed May 3, 2020.

32. Corbett GA, Milne SJ, Hehir MP, et al. Health anxiety and behavioural changes of pregnant women during the COVID-19 pandemic. Eur J Obstet Gynecol Reprod Biol 2020.

33. Huang JW, Zhou XY, Lu SJ, et al. Dialectical behavior therapy-based psychological intervention for woman in late pregnancy and early postpartum suffering from COVID-19: a case report J Zhejiang Univ Sci B 2020; 1-6.

34. Khan $S$, Peng $L$, Siddique $R$, et al. Impact of COVID-19 infection on pregnancy outcomes and the risk of maternal-to-neonatal intrapartum transmission of COVID-19 during natural birth. Infect Control Hosp Epidemiol 2020; 19:1-3.

35. Li S, Wang $Y$, Xue J, et al. The impact of COVID-19 epidemic declaration on psychological consequences: A study on active Weibo users. Int J Environ Res Public Health 2020; 19:17(6). Dialectical behaviour therapy-based psychological intervention for women in late pregnancy and early postpartum suffering from COVID-19: a case report.

36. Li NP, van Vugt M, Colarelli SM. The evolutionary mismatch hypothesis:
Implications for psychological science. Curr Dir Psychol Sci 2018, 27(1):38-44.

37. Usher K. The COVID-19 pandemic and mental health Impacts. Int J Ment Health Nurs 2020; 29:315-318.

38. Wray, M. China's divorce rates rise as couples emerge from coronavirus quarantine. Global News. 2020. Available at: https:// globalnews.ca/news/6767589/china-divorcerates-coronavirus/ Accessed May 3, 2020.

39. Chynoweth SK, Amsalu R, Casey SE, McGinn T. Implementing sexual and reproductive health care in humanitarian crises. Lancet 2018; 391 (10132):1770-1.

40. Arachchi, N.S.M., Ganegama, R., Husna, A.W.F. et al. Suicidal ideation and intentional self-harm in pregnancy as a neglected agenda in maternal health; an experience from rural Sri Lanka. Reprod Health 2019; 16, 166

41. Tabb KM, Gavin AR, Faisal-Cury A, et al. Prevalence of antenatal suicidal ideation among racially and ethnically diverse WIC enrolled women receiving care in a Midwestern public health clinic, J Affect Disord 2019; 256(1):278-281

42. Bhushan NL, Krupp K, Jaykrishna P, et al. The association between social support through contacts with Accredited Social Health Activists (ASHAs) and antenatal anxiety among women in Mysore, India: a cross-sectional study. Soc Psychiatry Psychiatr Epidemiol 2020.

43. Friedman LE, Gelaye B, Sanchez E, et al. Association of social support and antepartum depression among pregnant women. J Affect Disord, 264: 201-205.

44. Ebuenyi ID, Bhuyan SS, Bain LE. Zika Virus infection and microcephaly: anxiety burden for women. Pan Afr Med J 2018.

45. Torous J. Keshavan M. COVID-19, mobile health and serious mental illness. Schizophr Res, 2020.

46. Jiang $X$, Denga L, Zhu $Y$, et al. Psychological crisis intervention during the outbreak period of new coronavirus pneumonia from experience in Shanghai. Psychiatry Research 2020; 286: 112903.

47. Gausman J, Langer A. Sex and gender disparities in the COVID-19 pandemic. J Womens Health 2020; 29(4):465-466.

48. Duan L, Zhu G. Psychological interventions for people affected by the COVID-19 epidemic. 
Lancet Psychiatry 2020; 7(4):300-302.

49. Stuebe A. Should infants be separated from

mothers with covid-19? First, do no harm.

Breastfeed Med 2020; 15(5). 